\title{
INCLUSION DISEASE IN CHILDHOOD
}

\author{
BY \\ N. E. FRANCE \\ From Queen Elizabeth Hospital for Children, London, and The Babies Hospital, New York
}

(Received for Publication January 2, 1951)

It is well established that many viruses produce inclusion bodies in the nucleus or cytoplasm of an affected cell, and that the morphological appearance of such inclusions may be pathognomonic of a particular infection (Pinkerton, 1950). Similar bodies may also result from the toxic action of certain heavy metals (Lee, 1933; Blackman, 1936; Olitsky and Harford, 1937). They are occasionally found in cirrhotic livers, and Russell bodies are frequent in many non-specific inflammatory lesions. In view of these facts, Cowdry, Lucas, and Fox (1935) stated that the finding of inclusion bodies should be accepted with caution as evidence of viral infection. When they are conspicuous without the aid of oil immersion microscopy, are focal in distribution, and are related to marked lesions in the surrounding tissue, it is probable that they indicate a viral infection.

Intranuclear inclusions are divided into two types (Cowdry, 1934). Type A inclusion bodies are represented by a mass of eosinophilic material in the centre of the nucleus with collections of basophilic substance near the nuclear membrane. Complete disintegration of the cell ultimately occurs, and such cells are accompanied by a noticeable reaction in the surrounding tissues. This variety is seen in herpes, yellow fever, varicella, etc. Type B inclusions show a similar acidophilic accumulation in the nucleus which pushes the other nuclear components towards the nuclear membrane. There is no extensive destruction and no severe tissue reaction. Both types, and particularly type $B$, have been found in a number of apparently healthy animals of various species (Cowdry et al., 1935).

In 1920 Jackson observed inclusion bodies in the salivary glands of guinea-pigs. The affected cells were greatly enlarged and contained type A intranuclear inclusions and numerous small intracytoplasmic inclusion bodies. Cole and Kuttner (1926) first isolated a virus from affected guinea-pigs and, since then, the association of the salivary gland virus with the morphologically distinct inclusion cells has been firmly established (Markham, 1938, Rosenbusch and Lucas, 1939). Identical cells have been discovered in rats (Thompson, 1932), mice (Thompson, 1934), monkeys (Cowdry and Scott, 1935a and b), and mole (Rector and Rector, 1934). Efforts to transfer the infection from one species to another have failed, and it is now recognized that the virus is strictly species specific (Kuttner and Wang, 1934).

Occasional reports of peculiar cells in human organs, almost invariably in infants and young children, have appeared in the literature since they were first described by Jesionek and Kiolemenoglou in 1904. These were regarded as representing protozoa until Goodpasture and Talbot (1921) recognized their similarity to the bodies described in the lesions of vaccinia (Tyzzer, 1906) and in the salivary glands of guinea-pigs (Jackson, 1920). It was later observed that these cells had the same morphology as those found in animals infected with a salivary gland virus. So far, however, attempts to isolate a virus from human material have failed (Kuttner and Wang, 1934). All affected cells are enlarged to a diameter of $20-40 \mu$ so that they are two to four times as large as unaffected cells (Fig. 1). Most authors point out that transitions from normal to abnormal cells are rarely if ever seen, although stages in the development of the inclusion bodies have been described (Cappell and McFarlane, 1947). Often there is a condensation of the cytoplasm to form a thick refractile cell membrane, a feature most prominent in those cells showing evidence of degeneration.

The intranuclear inclusion bodies are two to three times as large as normal unaffected nuclei. Although usually round or oval, they may be reniform or distorted into bizarre shapes. They are acidophilic and often homogeneous, although sometimes they appear to be composed of numerous tiny particles.

A clear halo invariably separates the inclusion from the nuclear membrane on which are small 
condensations of chromatin ('orbital bodies'). One of these is normally considerably larger than the others and, when the inclusion body is reniform, this chief orbital body lies opposite the indentation. While one inclusion in each nucleus is the rule, two or more may be present. There is usually a single body in each nucleus in multinucleated cells.

Compared with the intranuclear inclusions, those in the cytoplasm are of restricted incidence, and appear only when the former are well developed (Pearson, 1930). They are numerous, round or oval and basophilic, and lie in the cytoplasm towards the unattached margin of the cell, sometimes forming regular rows. The overlying double-contoured cell membrane may be thinned, and the cytoplasm may bulge and produce an acorn-shaped cell (Cappell and McFarlane, 1947). Vacuolation of the cytoplasm is frequent.

Animals infected with a salivary gland virus exhibit no signs of disease. Many instances have now been described of human cases in which isolated lesions of a similar type were found in single organs at necropsy. In the majority sufficient cause for death was found, and there was no suggestion that a virus disease had caused symptoms or had affected the course of the primary disease. In 23 cases, however, lesions were present in many organs and, in some of these, there was no co-existing disease.

The purpose of this paper is to report four cases of generalized inclusion disease, to summarize six cases where lesions were found in one or two organs only, and to attempt to elucidate the clinical features of the disease as it occurs in children.

\section{Case Reports}

Case 1. P.G., a white British girl, aged 4 months, was the first child of healthy parents. The Wassermann and Kahn reactions of the mother's blood were negative. The infant was delivered normally at term, weighing $2,950 \mathrm{~g}$. When 3 days old she developed jaundice which became very intense and then diminished slightly. During the first 18 days of life she passed only three stools all of which were black. The umbilical cord separated on the seventh day, but the umbilicus continued to bleed slightly. A purulent nasal discharge began at the age of 14 days.

When 18 days old, the patient weighed 2,440 g., and was wasted and apathetic. Her temperature was subnormal $\left(95-96^{\circ}\right.$ F.) and her pulse slow $(92-120$ per minute). The forehead was deeply wrinkled. The isthmus of the thyroid was palpable. Generalized jaundice was marked, and the liver edge was palpable $2 \mathrm{~cm}$. below the right costal margin. The spleen could not be felt. Although the umbilicus bled easily, there was no obvious omphalitis.

LABORATORY INVESTIGATIONS. When the patient was 18 days old, laboratory investigations were made and gave the following results: Hb. $120 \%$; R.B.Cs., 6 million per c.mm.; W.B.Cs., 7,000 per c.mm. (polymorphs, $52 \%$, lymphocytes, $26 \%$ ).

The mother's blood group was A Rh positive (Anti-C +, Anti-D +, Anti-E -), and the child's, Group A Rh positive (Anti-C +, Anti-D +, Anti-E -).

The urine contained no bile. The direct Van den Bergh reaction was negative, and the indirect weakly positive. Culture from the umbilicus produced a scanty growth of Staphylococcus aureus (coagulase positive). The serum cholesterol level was $212 \mathrm{mg}$. \%.

Course. Test feeding on admission to hospital showed that the mother had a poor supply of breast milk and complementary feeding was started. The jaundice gradually diminished, and had completely cleared by the age of 31 days. Regular daily motions began and, with a caloric intake of 132 calories per $\mathrm{kg}$. body weight, the infant regained her birth weight at 46 days. She remained difficult to feed, never opened her eyes, and was extremely lethargic. At 9 weeks, the child was clinically an unmistakable cretin with an umbilical hernia, and marked supraclavicular and axillary pads. A radiograph of the skull and long bones showed marked immaturity with retardation of osseous development. An electrocardiogram revealed slight S-T deviation in lead 2 and low voltage P-T waves, most marked in lead 1 . The serum cholesterol level was $186 \mathrm{mg}$. \%. At this time treatment with thyroid extract was begun (grain $\frac{1}{8}$ b.d., gradually increasing to grain $\frac{1}{4}$ t.d.s.).

After 11 days' treatment there was a great change in the infant, who now weighed $3,520 \mathrm{~g}$. and had a normal temperature and a pulse rate of 120-130 per minute. She fed well and motions became regular. Good progress was made until four weeks after thyroid therapy was begun when pyrexia, diarrhoea, and vomiting appeared. Thyroid extract was discontinued; she was given glucose-saline by mouth only, and penicillin therapy was started. Three days later dehydration developed, and intravenous fluids were given. The stools became very pale, and jaundice and slight hepatomegaly were noted. By the twelfth day of this acute episode she was deeply jaundiced, the stools were white, and the urine deeply bilestained. The liver extended to the umbilicus. Three days later, however, all signs rapidly disappeared, and the liver became barely palpable. Thyroid extract was given again. She remained well for only six days when there was a recurrence of diarrhoea, abdominal distension, and dehydration. Despite intravenous therapy and a small blood transfusion, her condition rapidly deteriorated, and she died after 11 days of acute illness.

NECROPSY FINDINGS. There was generalized jaundice over the whole body, with evidence of moderate loss of weight.

Both lungs were well expanded and showed no evidence of disease.

The spleen $(10 \mathrm{~g}$.) was firm. Its cut surface was a homogeneous light brown with indistinct Malpighian bodies. An intense Prussian blue was produced when it was treate with potassium ferrocyanide and dilute hydrochloric acid.

The liver (162 g.) was greenish-brown on both its external and cut surfaces. The lobular pattern was 
indistinct. The gall bladder contained a little dark green bile and the hepatic and common bile ducts were patent.

Both kidneys (right, $20 \mathrm{~g}$.; left, 21 g.) appeared normal.

The thyroid gland $(3 \cdot 4 \mathrm{~g}$.) was of normal size and appearance.

Apart from a minor degree of bile-staining of all organs, no other abnormalities were found.

MICROSCOPY. The general architecture of the thyroid (Fig. 2) was distinctly abnormal. In most places it was difficult to distinguish an acinar arrangenent, the secretory cells having apparently proliferated and obliterated the lumina. The cells varied in size and shape, most having an irregular outline. The nuclei tended to be round or oval with a vesicular chromatin network, but often they were crenated and possessed denser chromatin. The cytoplasm was faintly eosinophilic and many of the larger cells showed small vacuoles. Where acini could be distinguished they were lined by irregular, vacuolated cells. The lumen often contained a few desquamated cells, but no colloid. Scattered throughout the gland were many large cells in various stages of degeneration and showing inclusions in their nuclei. The typical arrangement of the chromatin into beads was frequently lacking. Intracytoplasmic granules were absent, the cytoplasm often being occupied by numerous small vacuoles. Inclusion cells were found both singly and in groups of up to about 30 . When isolated, they lay either in the walls of acini or amongst proliferated secretory cells, and they showed no associated inflammatory reaction. When in groups it was often impossible to determine whether they lay in secretory tissue or in interstitial tissue. Such collections were surrounded by varying numbers of lymphocytes and plasma cells which extended locally into the adjacent interstitial tissue. Nowhere was there any evidence of fibrosis.

The general architecture of the liver was normal. The majority of the hepatic cells throughout the lobule contained small granules of haemosiderin. A few cells showed moderate fatty change, and some possessed two or three nuclei. There were many bile plugs in dilated canaliculi. The portal tracts were generally normal, but here and there inclusion cells completely occluded the lumina of the small bile ducts. They were invariably single, and were less degenerate than those in the thyroid. Intracytoplasmic inclusions were generally absent.

A few inclusion cells, occurring singly or in pairs, were present in the tubules of the renal cortex, lying between normal cells and projecting into the lumen which was never dilated. Intracytoplasmic granules were prominent. There was no inflammatory reaction.

Except for occasional inclusion cells within the acini, the pancreas was normal.

Several isolated inclusion cells were found in the alveoli of the lungs, where they were apparently attached to the alveolar walls. Throughout both lungs, many of the alveoli contained mononuclear cells.

Several degenerate inclusion cells were present in the anterior pituitary. They occurred singly and produced no inflammatory response.

Both the submaxillary salivary glands showed numerous inclusion cells, mainly in the small ducts where several were frequently adjacent. A few were present in the acini. All were degenerate, and surrounded by a well marked inflammatory exudate in the interstitial tissue. This consisted mainly of lymphocytes and plasma cells. Cytoplasmic granules were evident in the majority of the inclusion cells.

In the spleen there was a considerable increase in the number of reticulo-endothelial cells in the pulp, almost all of which contained coarse granules of haemosiderin.

No abnormalities were noted in any other organ.

The main lesions were cretinism (clinical); enteritis (clinical); and inclusion cells in thyroid, salivary gland, liver, kidney, lung, pancreas, and pituitary.

Case 2. D.S., a white American girl, aged 14 days, was born of healthy parents by breech delivery without instruments after a labour lasting four or five hours. The infant was slightly icteric at birth, and small red spots were present over the whole body. Her birth weight was $2,320 \mathrm{~g}$.

A physical examination was made on the fifth day. The child weighed 2,240 g., and was $44 \mathrm{~cm}$. long. She was very small, particularly her head which was $29 \mathrm{~cm}$. in circumference. Generalized purpuric lesions and jaundice of the skin were noted. Small, hard lymph nodes were palpable in the cervical, axillary, and inguinal regions. The liver edge was $5 \mathrm{~cm}$. below the right costal margin, and the spleen $4 \mathrm{~cm}$. below the left costal margin. There was a fine tremor of the arms when the infant cried. All other systems were normal.

LABORATORY INVESTIGATIONS. On the sixth day a blood examination gave Hb. 10.9 g. \% ; R.B.C.s 2.9 million per c.mm.; platelets 16,000 per c.mm.; W.B.C.s 6,200 per c.mm. (polymorphs, 26\%, lymphocytes, 66\%; monocytes, 4\%; eosinophils, 2\%; basophils, $2 \%$ ). The coagulation time was $4 \frac{1}{2}$ minutes, and the bleeding time $4 \frac{1}{2}$ minutes. The infant's blood was $\mathrm{Rh}$ positive. On the seventh day the platelets were 10,000 per 100 W.B.C.s.

Examination of the urine on the sixth day gave albumin +++ , bile + , W.B.C.s 4-6 per high power field. Mary micro-organisms were seen; 2-4 leucocytic, granular, and mixed hyaline casts per high power field. On the tenth day an occasional white cell was present, 0-4 granular and hyaline casts per high power field.

The blood culture on the fifth day showed no growth.

The cerebrospinal fluid on the seventh day showed protein $146 \mathrm{mg}$. \%, sugar $35 \mathrm{mg}$. \%, chlorides $722 \mathrm{mg} . \%$. On culture Staphylococcus albus (coagulase negative) was isolated. On the tenth day the C.S.F. was clear and xanthochromic.

A radiograph was taken on the sixth day and showed that the sutures of the skull were widely separated with diffuse calcification involving both parietal regions of the brain. The findings were considered to be typical of toxoplasmosis.

Transfusions of $30 \mathrm{ml}$. of whole citrated blood were given on the seventh and eleventh days without improvenent.

When seven days old, the baby had several convulsive attacks consisting of clonic jerks and twitchings of both 
arms. Her respirations finally became laboured and during the last three days the temperature fell to the region of $94^{\circ} \mathrm{F}$.

NECROPSY FINDINGs. The body was mildly jaundiced, and moderately emaciated.

Both lungs were well expanded with small areas of emphysema.

The liver (123 g.) had a smooth, dark, brownish-green capsule mottled by deeper red areas. It was moderately firm. The cut surface was brownish-green and showed normal lobular markings. The gall bladder contained dark green bile.

The pancreas and spleen (35 g.) appeared normal.

The thymus $(1 \mathrm{~g}$.) showed a poorly defined lobular pattern. Small punctate haemorrhages were present beneath the pleura and pericardium and into the mucosa of the ileum and bladder. Apart from generalized bilestaining all other viscera were normal.

The brain was small with a normal gyral pattern, obscured in places by a greyish yellow discoloration of the leptomeninges. Two such areas were present over the left temporal and right central regions measuring $1 \cdot 2$ and $0.6 \mathrm{~cm}$. in diameter respectively. The cortex beneath these areas showed punctate yellow discoloration and a number of tiny haemorrhages. There was a slightly protuberant, poorly defined area of increased density about $0.8 \mathrm{~cm}$. in diameter in the anterior portion of the right temporal lobe. On section the lateral ventricles were of normal size. There were linear, serrated bands of dull, yellowish white tissue in the cortex of many of the gyri in the frontal, temporal, and parietal lobes. In some places this abnormal layer was punctate due to the interposition of semi-translucent, greyish tissue between the yellowish areas. Similar lesions were present beneath the ependyma of both lateral ventricles, and a few yellowish areas up to $1 \mathrm{~mm}$. in diameter were seen in the left basal ganglia and the left thalamus. The cerebellum, brain stem, and spinal cord showed no gross abnormalities.

MicrosCOPY. The majority of the alveoli of the lungs contained granular material, red blood cells, cornified amniotic cells, large vacuolated mononuclear cells, and many bacteria. Similar elements were in the bronchi and bronchioles. A few alveolar ducts were dilated and lined by hyaline membrane. There were occasional typical inclusion cells in the alveoli, the majority of which lay alongside the wall to which they appeared to be attached; others lay freely in the alveolar spaces.

The normal architecture of the liver was distorted by an increased amount of connective tissue in the portal areas and between the hepatic cords in some lobules. Many newly formed bile ducts contained plugs of bile, and there were granules of haemosiderin both in liver cells and in the swollen Kupffer cells. There were many foci of haemopoiesis. Only in the smaller bile ducts were inclusion cells seen, and in several places it appeared that they completely obstructed the flow of bile.

A number of acini in the pancreas were distended by an eosinophilic secretion with flattening of the acinar cells. Between the acini there was increased connective tissue in which there were moderate numbers of myeloid cells. Scattered inclusion cells lay in acini and the islets of Langerhans (Fig. 3).

Many of the convoluted tubules of the kidney contained inclusion cells, as many as 20 being present in the cross section of a single tubule. The majority of the affected tubules were considerably dilated, and often surrounded by a lymphocytic infiltration into the interstitial tissue. The affected tubules were mainly in the outer half of the cortex. There were small foci of haemopoiesis in the tissues surrounding the pelvis.

In the thyroid occasional colloid-filled acini contained a single inclusion cell, and here and there collections of typical cells completely obliterated the lumen.

The thymus showed accidental involution.

The pulp of the spleen contained many small foci of haemopoiesis without any obvious deposit of haemosiderin.

Large areas of the cortex of the brain were destroyed to form sharply defined, irregular zones in which there were innumerable basophilic granules either within degenerate nerve cells or forming round clusters. The arrangement of the nerve cells in the surrounding tissue was disturbed by mild astrocytosis. Calcified zones were present in the underlying white matter where there were occasional large plates of calcium in the corpus striatum and in the subependymal tissue. Many small collections of marginal cells were found in the region of the aqueduct and in one corpus quadrigeminum. The remainder of the brain stem and the spinal cord were normal.

The main lesions were calcification of brain with microcephaly; cirrhosis of the liver; cystic fibrosis of the pancreas; and inclusion cells in the lungs, liver, pancreas, kidney, and thyroid.

Case 3. D.G., a coloured American girl, aged $85^{\circ}$ days, was born prematurely after a spontaneous delivery. The birth weight was $1,070 \mathrm{~g}$. She was well until she was 72 days old when the labia became swollen and tender, and a reducible hernia in the left groin was noted. This remained visible for ten days when it began to disappear. Four days later snuffles began accompanied by swelling of the left thigh.

On the 77th day, a physical examination showed that the sternum retracted on inspiration, and a faint cry was emitted on expiration. There was a small umbilical hernia. Both liver and spleen were palpable $1.5 \mathrm{~cm}$. below the costal margins. The vulva, perineum, and buttocks were reddened and oedematous. There was a firm swelling, $4 \mathrm{~cm}$. in diameter, over the upper lateral aspect of the left thigh. Although it appeared to be tender it caused no limitation of movement. Dactylitis was seen in both hands.

LABORATORY INVESTIGATIONS. A blood count gave the following: Hb. $65 \%$, R.B.C.s $3.41 \mathrm{~m}$. per c.mm., W.B.C.s 10,000 per c.mm. (polymorphs, 78; lymphocytes, 19; myelocytes, 2; myeloblasts, 1). There were hypochromia and anisocytosis and less than one normoblast per 100 W.B.C.s. The urine showed a trace of albumin only. Vaginal and throat cultures revealed no pathogens. Blood culture was negative. The Kahn test was ++ .

The general and local conditions remained about the same until the infant was 82 days old, when stridor 


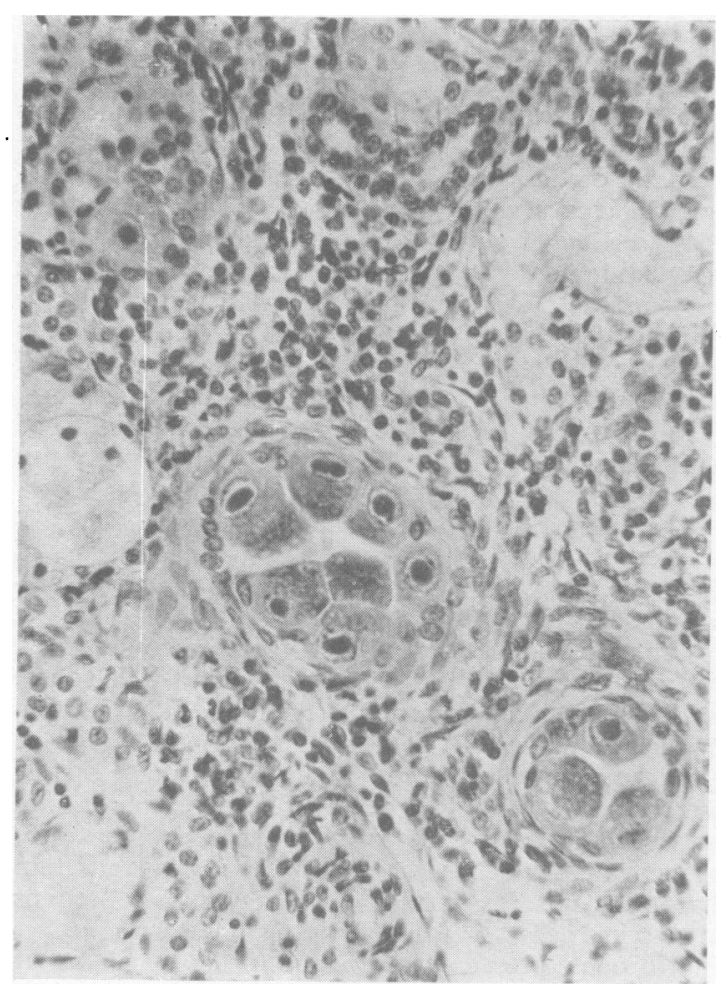

FIg. 1.-Typical inclusion cells in renal tubules of Case 2 ( $\times 280)$.

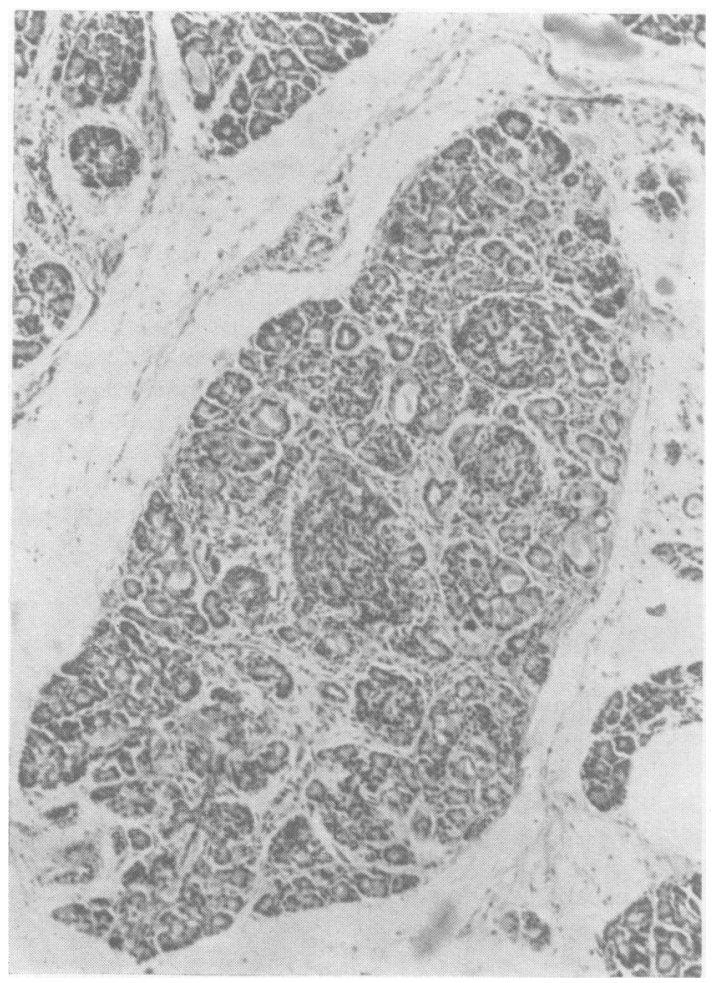

FIG. 3.-Pancreas of Case 2 showing mild cystic fibrosis with scattered inclusion cells $(\times 89)$.

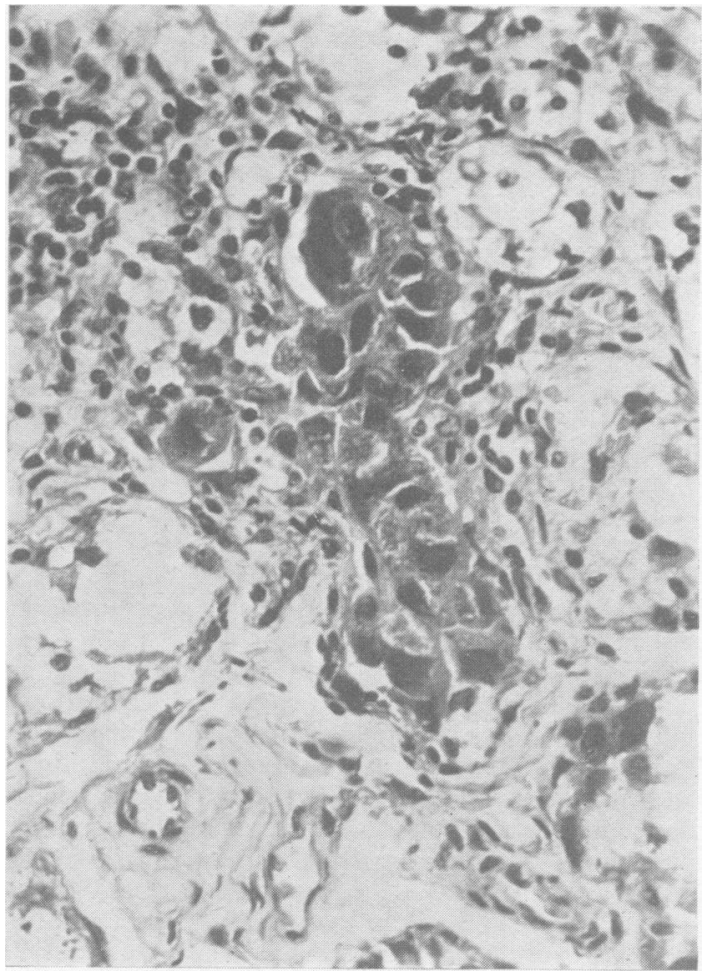

FIG. 2.-Thyroid gland of Case 1 showing collections of degenerating inclusion cells $(\times 380)$.

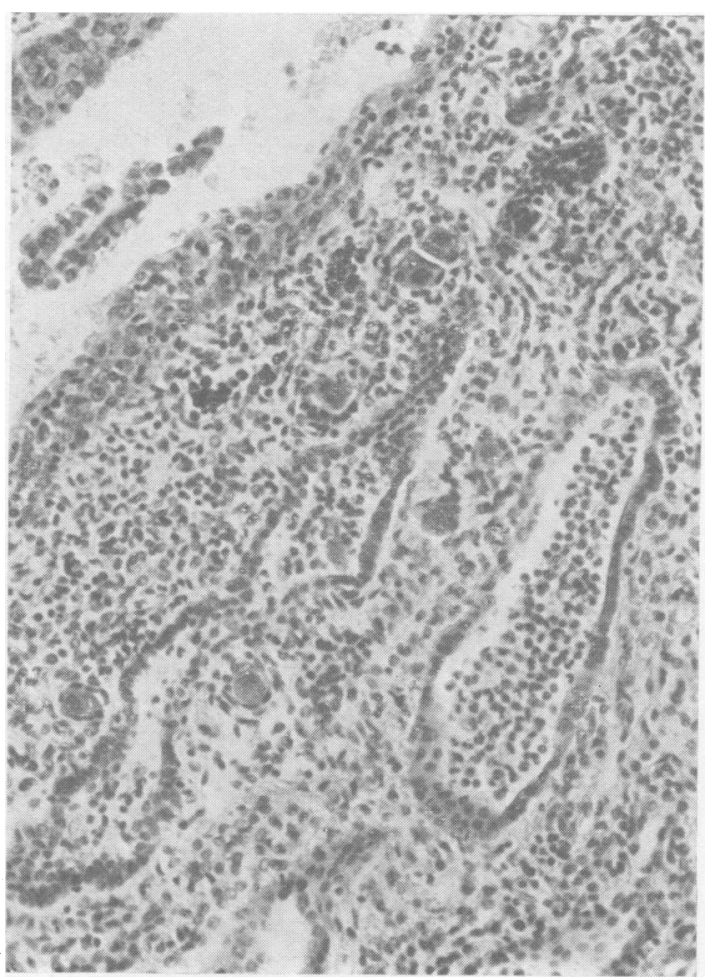

Fig. 4.-Kidney of Case 4 showing inclusion cells associated with collecting tubules and ascending pyelonephritis $(\times 175)$. 
increased and there was marked depression of the sternum. The swelling of the buttocks and perineum lessened. An x-ray examination of the chest showed perihilar bronchopneumonia with emphysema of the left lung. The child rapidly became exhausted and died.

NECROPSY FINDINGS. The body was emaciated with a definite icteric tinge to the skin. There was a firm swelling of the upper half of the left thigh, and swellings of the middle phalanges of the right index and left middle fingers.

The lungs showed patches of emphysema anteriorly in all lobes.

The spleen (16 g.) had a soft, congested surface.

The liver (145 g.) was firm and brown with a greenish tinge. The cut section was even.

The gall bladder was rudimentary and contained a small amount of thick, dark green bile.

Both kidneys (right, $7 \cdot 5 \mathrm{~g}$.; left, $8 \cdot 0 \mathrm{~g}$.) appeared normal. The muscles attached to the upper end of the left femur were pale and of a yellowish-tan, and stripped readily from the underlying bone. The femur fractured transversely at a point just below its neck where the cortex was thickened. Here the marrow was pale and tough, resembling granulation tissue. Just above the irregular epiphyseal line at the lower end of the femur was a soft white area measuring $4 \times 3 \mathrm{~mm}$. The lower ribs on both sides were beaded and on section showed irregular epiphyseal lines.

A small amount of clotted blood lay over the left hemisphere of the brain.

All the other organs were of normal size and appearance.

Microscopy. Many liver cells contained fat droplets, and in the region of the portal tracts occasional multinucleated cells were seen. Numerous foci of haemopoiesis were scattered throughout. There was a slight increase of connective tissue in the portal areas. No bile plugs or iron pigment could be demonstrated. In one portal area six typical inclusion cells completely blocked the lumen of a medium sized bile duct.

The general architecture of the pancreas was normal but occasional inclusion cells were seen in the acini.

In the lungs the alveoli contained large mononuclear cells in great numbers. Attached to the wall of one alveolus were several inclusion cells.

Large numbers of inclusion cells were present in the cortex of the kidneys, mainly in the outer half. They formed part of the epithelium of many of the convoluted tubules, as many as $\mathbf{3 0}$ being present in the cross section of a single tubule. Many affected tubules were considerably dilated, and some of these contained pink homogeneous material. Large areas of cellular infiltration were related to collections of inclusion cells. These consisted of lymphocytes, plasma cells, and occasional mononuclear cells. A few glomeruli showed capsular thickening but none was completely fibrosed.

In the periosteum of the upper end of the femur there were numerous polymorphs. The overlying muscle was oedematous, but showed no inflammatory infiltration. The marrow at both ends of the femur and in the upper end of the tibia was replaced by areas of granulation tissue.
Phalanges from both affected fingers showed granulation tissue, bone degeneration, and irregularity of the epiphyseal lines typical of syphilitic dactylitis. The spleen appeared normal and contained no haemosiderin. A single inclusion cell was found in a parathyroid gland. All other organs were normal.

The main lesions were congenital syphilis; acute osteomyelitis; and inclusion cells in liver, pancreas, lung, kidney, parathyroid.

Case 4. M.S., a coloured American girl, aged 57 days, was born after seven months' gestation. Birth was normal, and the child weighed 2,220 g. She was breast-fed for two and a half weeks and then artificially fed. Constipation was marked from birth, the stools being hard and bright yellow or green. During the week before admission to hospital at the age of 50 days she developed a cold with a skin rash.

Emaciation was marked, and icterus of the skin and sclera was evident. The liver was palpable $3 \mathrm{~cm}$. below the right costal margin. No other abnormalities were found, and a diagnosis of a bile duct anomaly was considered.

During her seven days in hospital the baby took fluids poorly, vomiting two to three times daily after feeds. Bile was present in the stools.

The van den Bergh reaction was ++++ (biphasic), and the benzidine test on the urine was positive. Many clumped white cells were found in the urine. The Kahn test was negative. The temperature became subnormal and respirations laboured with an expiratory grunt for several days before death.

NECROPSY FINDINGS. The body showed evidence of considerable loss of weight and moderate generalized icterus.

The lungs showed marked emphysema of the anterior parts only, with increased consistency of the right lower lobe.

The liver (80 g.) was dark green, but had normal markings. The common, cystic, and hepatic ducts were explored and found to be patent.

Both kidneys (right, $13 \mathrm{~g}$.; lęft, 12 g.) were mildly swollen, and the entire surface was mottled with yellowish-grey, opaque areas measuring 1-10 $\mathrm{mm}$. in diameter. On section, these areas extended deeply into the cortex and in some places into the medulla. The boundary between the cortex and the medulla was blurred. All other organs appeared normal.

Microscopy. The spleen showed increased cellularity of the pulp and marked haemosiderosis. With the exception of numerous granules of haemosiderin in most of the cells, the liver cords were normal. Bile plugs were present in some canaliculi. The Kupffer cells were enlarged and contained haemosiderin. The portal tracts were relatively cellular and showed no evidence of fibrosis. Several typical inclusion cells were present in the region of the portal tracts, but it was not possible to demonstrate their exact location in the bile ducts.

Triangular areas in the kidneys extended from the capsule to the pelvis. In these areas there was an extensive infiltration of polymorphs which almost obliterated the normal architecture. The tubules were filled with leucocytes, and their epithelium flattened, 
whilst there was a polymorphonuclear and lymphocytic infiltration of the interstitial tissue, forming, in some regions, definite abscesses. Inclusion cells were present in the distal parts of some of the collecting tubules in the region of the pelvis. Occasional inclusion cells were surrounded by a mild infiltration of lymphocytes and polymorphs (Fig. 4). No typical cells were present in the cortex.

The alveolar walls of the lung were generally markedly thickened and infiltrated with lymphocytes, plasma cells, and mononuclears. In a few alveoli typical inclusion cells were present, some being attached to the alveolar wall.

The bronchi contained cellular exudate but the epithelial lining was generally well preserved. In the peribronchial regions, however, there was an infiltration of lymphocytes and plasma cells.

The main lesions were ascending pyelonephritis ; interstitial pneumonia; and inclusion cells in liver, kidneys, and lungs.

\section{Summary of Cases with Minimal Lesions}

The clinical and pathological findings of six cases in which scanty inclusion cells were found in one or two organs are summarized in Table 1. Only one of the children was over 7 months of age. It is doubtful if infection by the salivary gland virus seriously affected the course of the primary disease in any case, although the possibility that it predisposed the infants to other infections cannot be ruled out. In Case 5 there was haemosiderosis of the liver which may have been due to the virus infection. The duodenal ulcers found in Case 7 were small superficial erosions of the first part of the duodenum. Many inclusion cells were found in the stroma, often close to capillaries, while others were located amongst epithelial cells, especially in Brunner's glands. The presence of inclusion cells in small numbers in many different organs, in the absence of gross pathological changes, emphasizes the fact that this infection is not uncommon, and that in the majority of cases it has little or no bearing on the clinical picture.

\section{Discussion}

Cases of Generalized Disease. From a study of the literature and from the cases described here the subject will be discussed under specific headings.

AGE AND SEx. Of the cases of generalized inclusion disease in children which have been described in the literature and including the four cases reported here (Table 2), there have been four stillbirths and 23 live births; 20 of the infants died within three months of birth. Eleven (almost 50\%) of the babies born alive died under the age of 28 days. No difference in sex distribution was found. In 22 cases where the sex was mentioned, 11 of each sex were included.

OBSTETRICAL History. Details of pregnancy were lacking in all but three cases, where it was said to be normal. Delivery was by breech in two cases, forceps were used in one case, while birth was normal in ten cases. Of 16 cases where the length of pregnancy was reported, seven were full term

TABLE 1

Summary of Six Cases with Minimal Lesions

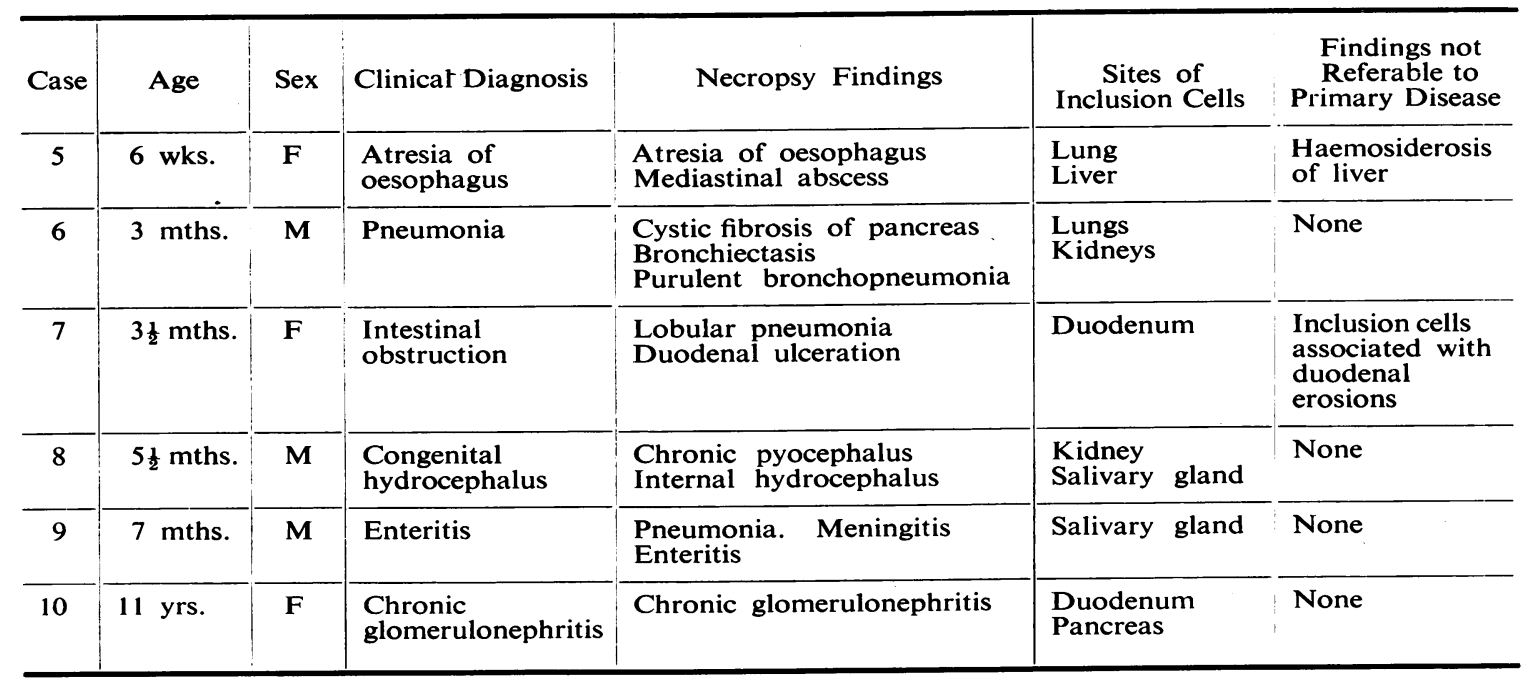




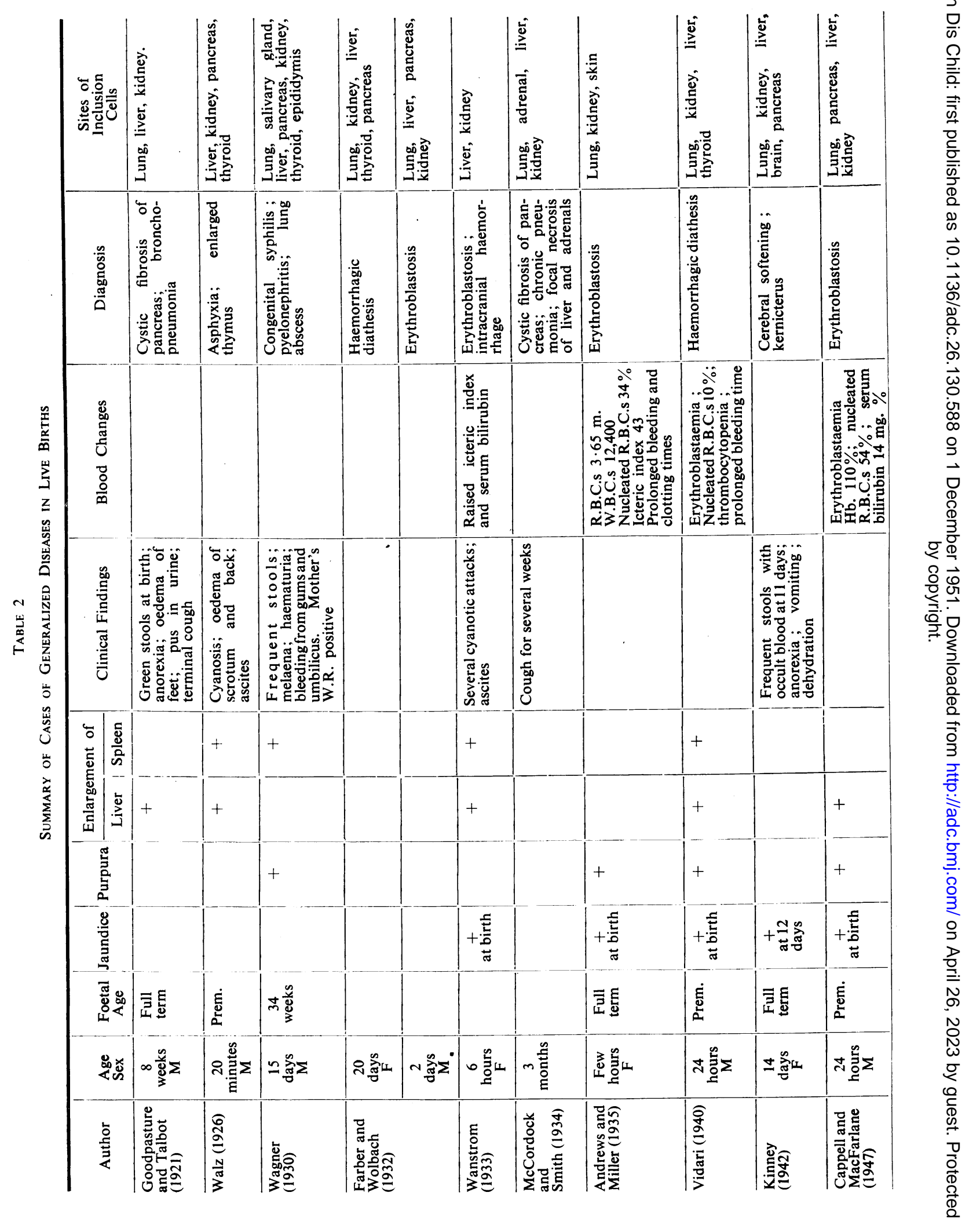




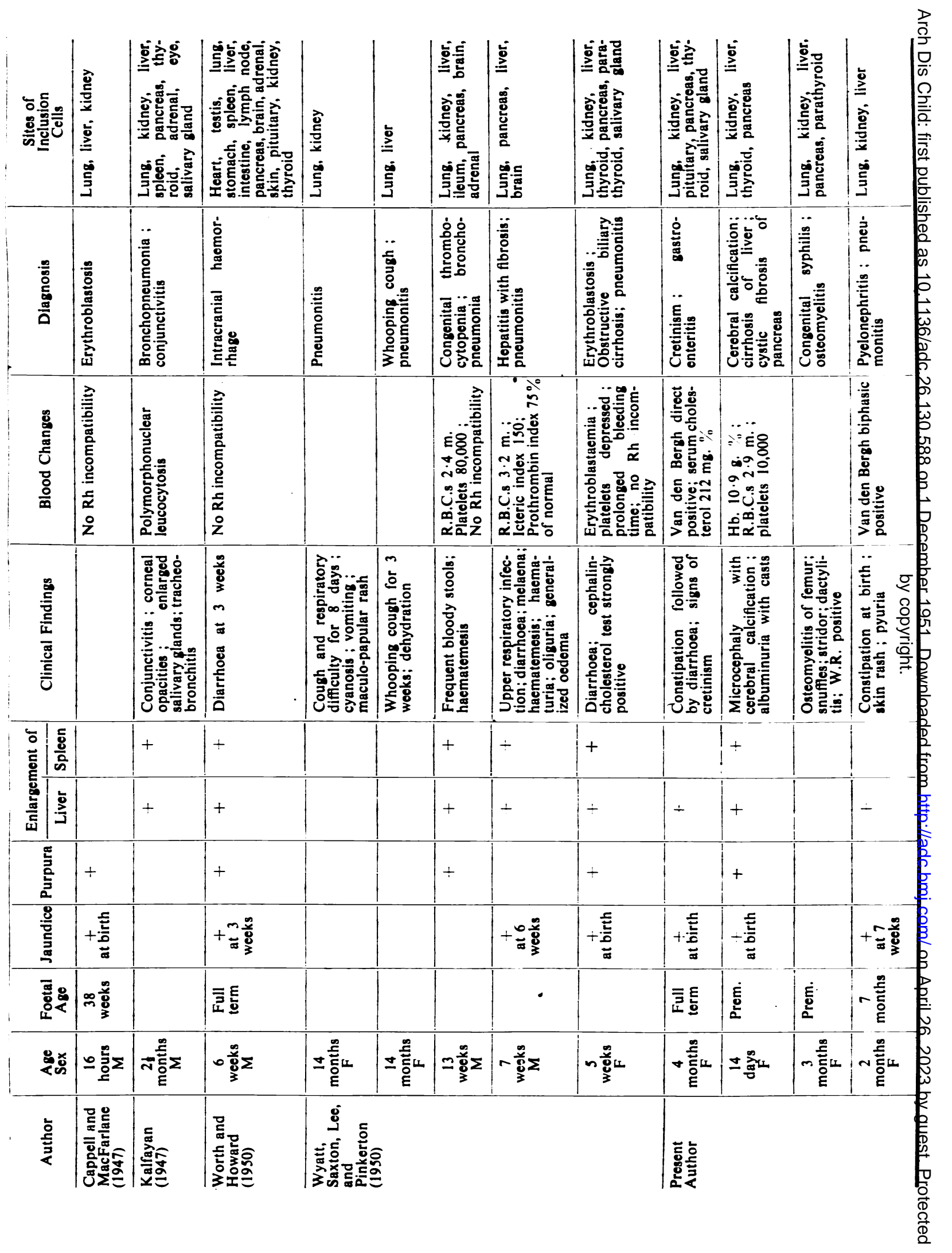


babies, while nine varied from 32 to 38 weeks of gestation.

Evidence of Syphilis. Two stillbirths (Jesionek and Kiolemenoglou, 1904; Pisano, 1910) were considered to have congenital syphilis on clinical and pathological grounds only. However, as Cappell and McFarlane (1947) pointed out, the cellular infiltration of the organs in these cases may have been partly due to extramedullary haemopoiesis, so that they possibly fall into the group of cases with evidence of haemolytic disease.

In Case 3 the Wassermann reaction was positive, while in Wagner's case (1930), the mother's serum was positive and the child's negative. In 13 other cases either the mother or child had negative reactions. It appears unlikely that the presence of syphilis was anything but coincidental, although it may have predisposed the infants to infection by the salivary gland virus.

STILlbirths. Except for the presence of inclusion cells in the kidneys, liver, and lungs, the case reported by Smith and Weidman (1910) showed no disease. These cells were present in appreciable numbers only in the kidneys where they were associated with an inflammatory reaction. In their series Wyatt, Saxton, Lee, and Pinkerton (1950) include a single stillbirth in which they demonstrated mild interstitial pneumonitis associated with inclusion cells. Two cases with inconclusive evidence of syphilis have already been mentioned. In none of these cases was purpura, jaundice, or hepatosplenomegaly noted. Walz (1926) described a premature boy who lived for 20 minutes, and in whom ascites was the most prominent feature.

HAEMOlYTIC Disease. That generalized infection by the salivary gland virus is often associated with haemolysis or a bleeding tendency is shown by the fact that of 23 live births reported in the literature no less than six clinically resembled erythroblastosis and two were diagnosed as 'haemorrhagic diathesis.' Six of these eight cases died within two days of birth. One case lived for 20 days (Farber and Wolbach, 1932), while another, which presented similar signs shortly after birth, survived for five weeks, finally dying with clinical and pathological evidence of cirrhosis (Wyatt et al., 1950, Case 6). In only three cases was the possibility of $R h$ incompatibility eliminated (Cappell and McFarlane, 1947; Wyatt et al., 1950).

Excluding the two cases mentioned by Farber and Wolbach (1932), where no details were given, and which were diagnosed as erythroblastosis and haemorrhagic diathesis respectively, the clinical features of the remaining cases were remarkably similar. Jaundice was present at or within a few hours of birth in all cases, and petechiae of the skin were present in five. Hepatosplenomegaly, often of marked degree, was usually present. Ascites was demonstrated clinically only once (Wanstrom, 1933), although slight ascites was occasionally found at necropsy. The red cell count was sometimes slightly below normal, the lowest recorded being 3.65 million per c.mm. (Andrews and Miller, 1935) whilst the haemoglobin level was usually within normal limits. The white cell count was usually normal with nucleated red cells representing 10 to $54 \%$ of the total nucleated elements. The bleeding time was stated to be prolonged in three cases, in one of which (Andrews and Miller, 1935) the clotting time was also prolonged. Thrombocytopenia was observed by Vidari (1940), and by Wyatt et al. (1950), in whose case a level of 23,000 per c.mm. was reached. The icteric index was raised in two cases, and in a third the serum bilirubin level was $14 \mathrm{mg}$. \%. Except for the presence of inclusion cells in a number of organs, the pathological findings were similar to those of erythroblastosis foetalis. Extramedullary haemopoiesis was always present in the liver and spleen, and was often found in the kidneys, lungs, pancreas, and other organs. Haemosiderin deposits tended to be small and, when present, were mainly in the liver.

It is noteworthy that in three other cases the question of erythroblastosis was raised. Case 2 in the present series showed jaundice and skin petechiae with marked hepatosplenomegaly, thrombocytopenia, and a blood count with three nucleated red cells per 100 white cells. The pathological findings could be explained on the basis of its being a case of erythroblastosis, although it was felt that the cerebral calcification was due to infection by toxoplasma. A minor degree of cerebral calcification was noted by Wanstrom (1933), who described calcified thrombi in the brain, and by Wyatt et al. (1950, Cases 4 and 6) who believed that it represented ependymitis. The high incidence of cerebral calcification in this group leads one to consider the possibility that it is due in some way to the viral infection, although conclusive evidence of such infection in the lesions is usually lacking.

Case 4 of Wyatt et al. (1950) also showed evidence pointing towards an initial diagnosis of erythroblastosis, but here thrombocytopenia and diffuse purpura dominated the picture. Thrombocytopenia has been observed on four occasions in the neonatal period, and appears to be a significant feature of the blood picture in those infants with signs of haemolytic disease.

Kernicterus has been reported only once (Kinney, 1942). This 14-day-old child developed jaundice three days before her death, but showed no obvious clinical or pathological signs of erythroblastosis. 
Irregular yellow areas of cerebral softening were found, associated with one of which was a single inclusion cell.

It may be concluded that where infection is present at birth a large percentage of cases clinically resemble erythroblastosis foetalis, purpura and thrombocytopenia often being prominent features. Infection by the salivary gland virus should be considered in the differential diagnosis of any newborn child with icterus, hepatosplenomegaly, and the blood picture of erythroblastosis foetalis in whom no blood group incompatibility can be demonstrated.

Pulmonary Involvement. The clinical picture was dominated by evidence of pulmonary pathology in only two cases (Wyatt et al., 1950, Cases 2 and 3). Both were 14 months old, and had suffered from pertussis for three weeks before death. The symptoms, signs, and x-ray findings were equivocal but at the necropsy the lungs showed septal pneumonitis with a lymphocytic and mononuclear inflammatory reaction associated with numbers of inclusion cells. Neither case presented any history suggestive of haemolytic disease. Kalfayan (1947) reported the case of a child of $2 \frac{1}{2}$ months who died of bronchopneumonia following intractable suppurative conjunctivitis. No signs or symptoms referable to the lungs were found other than those of bronchopneumonia. Histological examination of the lungs showed areas of fibrosis and round cell infiltration together with numbers of inclusion cells. A similar septal pneumonitis was also found in the necropsy of a 13-week-old child dying with purpura and thrombocytopenia (Wyatt et al., 1950, Case 4).

The existence of pneumonitis in cases of generalized viral disease is of interest when the observations of workers on the lungs of children dying of pertussis are considered. Feyrter (1927) was the first to observe inclusion cells identical with those produced by the salivary gland virus in the alveoli and peribronchial tissues of a $2 \frac{1}{2}$-year-old girl dying of pertussis and measles. In 1932, Rich found similar cells in five cases of whooping cough, but he emphasized that, as only two showed any appreciable infiltration of the bronchial walls, one should guard against considering such a reaction as being caused by a virus. McCordock and Smith (1934) demonstrated typical inclusion cells in the lungs of 18 out of 40 cases of pertussis dying between the ages of a few weeks and 5 years. They also found inclusion cells in the lungs of five children between 3 months and 2 years who at necropsy showed chronic pneumonia with peribronchial infiltration. Kinney (1942) added four similar cases of clinical whooping cough. While it is possible that this is merely an incidental association, some other explanation is more likely. The condition clinically resembling whooping cough may be a distinct entity caused by the virus; a latent endogenous virus may be activated by infection with the Haemophilus, or the virus may enter the lungs as a secondary invader (McCordock and Smith, 1934).

Of equal interest is the finding of inclusion cells in the lungs of children with cystic fibrosis of the pancreas. This was first described by Goodpasture and Talbot (1921) who found large numbers of inclusion cells in the inflammatory areas of the lungs, especially within the walls of the chronically inflamed bronchi. Two other cases were mentioned by McCordock and Smith (1934). In none of these were inclusion cells present in the pancreas. They have, however, been described on 13 occasions in the acini and ducts of the pancreas in the absence of cystic fibrosis. No conclusions can be based on such a small series, especially when one considers that the presence of these cells in a single organ, particularly the salivary glands, is not uncommon.

Hepatitis. Clinical and pathological evidence of hepatitis or cirrhosis has been noted in three cases. A 7-week-old boy described by Wyatt et al. (1950, Case 5) after an initial history of acute otitis media, vomiting, and diarrhoea, showed progressive hepatosplenomegaly, and during the last week of life, severe jaundice. Bile was constantly present in the urine. Hepatitis was diagnosed during life, and at necropsy centrilobular necrosis and periportal fibrosis were found in the liver. Case 6 of these authors, a 5-week-old girl, resembled erythroblastosis foetalis during the neonatal period, but during the last two weeks of life showed evidence of liver damage. Urobilinogen and bilirubin were present in the urine, and the cephalin-cholesterol flocculation test was strongly positive. Necropsy showed obstructive biliary cirrhosis with degeneration of the liver cells in both central and peripheral zones of the lobules. Although there was no clinical suggestion of liver disease in Case 2 in the present series, biliary cirrhosis was found at necropsy.

In view of the frequency with which obstruction of the small biliary ducts occur, it is not surprising that, when life is prolonged beyond the neonatal period, some form of liver damage should supervene. Mild cirrhosis could be the direct result of the obstruction to the flow of bile, although it is difficult to explain the production of the histological lesions of typical virus hepatitis on these grounds. There is little evidence to suggest that the salivary gland virus exerts a necrotizing effect. On the contrary, the lesions in this disease are usually free of necrosis. 
PyelonePHRITIS. The kidneys are almost invariably affected in the generalized disease, often showing the most marked pathological lesions. Although the inclusion cells are usually surrounded by a mild inflammatory reaction, acute inflammation has only been seen on two occasions. Wagner (1930) found haemorrhagic cystitis and ascending pyelonephritis with abscess formation in a 15-day-old syphilitic child, a condition which was not suspected during life. Case 4 in the present series showed numerous pus cells in the urine and ascending pyelonephritis was demonstrated at necropsy. These cases are undoubtedly due to superadded infection rather than to the action of the salivary gland virus. It is rare to find any changes in the urine referable to kidney disease even when the kidneys are extensively involved, although Wyatt et al. (1950) have suggested that inclusion cells may possibly be found in the urine during life.

ENDOCRINE INVOLVEMENT. Involvement of the endocrine glands is comparatively frequent. Inclusion cells were present in the adrenal glands in five cases, in the parathyroids in two cases, and in the pituitary gland in one case. They have been found in the thyroid gland in no less than nine cases of generalized disease (Walz, 1926; Wagner, 1930; Farber and Wolbach, 1932; Vidari, 1940; Kalfayan, 1947; Worth and Howard, 1950; Wyatt et al., 1950; Cases 1 and 2 of the present series), and as an isolated finding in one case (Pettavel, 1911). Only in Pettavel's case was endocrine dysfunction noted, the lesions in the thyroid being associated with neonatal goitre.

The presence of definite thyroiditis in Case 1 with numerous foci of inflammation diffusely scattered throughout the gland, and the fact that lesions were more numerous in the thyroid than in any other organ, suggest that the infection may have caused signs of hypothyroidism by its direct action on the thyroid gland. The gland, however, was abnormal in other ways. The acini were small, the lining cells were irregular and appeared to have proliferated, and there was a total absence of any evidence of active secretion. The picture was quite unlike that usually seen in cases of cretinism. It is difficult to visualize how a focal inflammation could have caused such generalized histological changes, especially when one considers that most of the cases previously described showed no such changes. The pituitary gland was directly involved and this may have secondarily inhibited thyroid activity. Although no definite conclusions can be drawn as to the actual mechanism involved, it appears certain that a connexion exists between the infection, its localization in the thyroid and pituitary glands, and the presence of hypothyroidism.
Gastro-intestinal Symptoms. Whilst the incidence of diarrhoea was high (eight of 23 cases), it was usually impossible to relate this to infection by the virus. The onset of the diarrhoea varied within wide limits, sometimes occurring within a few days of birth, at other times not appearing until shortly before death. Its severity was likewise very variable. In four cases diarrhoea was associated with vomiting.

Hepatomegaly, usually with splenic enlargement, was recorded in 13 cases. In the majority of these it was quite independent of any gastro-intestinal symptoms, although, as in Case 1, the degree of enlargement sometimes varied with the severity of the diarrhoea.

Inclusion Cells in Single Organs Only. Typical lesions have been observed in single organs of children dying of a great variety of diseases. Only in the case of neonatal goitre (Pettavel, 1911), and in those cases of whooping cough (McCordock and Smith, 1934, and others), did their presence in the body appear to have been significant.

Where routine examinations of the salivary glands have been performed inclusion bodies were found in a high percentage of children. The series of Farber and Wolbach (1932) where inclusion cells were found in the salivary glands of 24 of 183 consecutive necropsies, confirmed observations on their occurrence by Ribbert (1904), Lowenstein (1907), and Wagner (1930). Further cases by McCordock and Smith (1934) and Kinney (1942) have produced 42 cases with lesions in the salivary glands only. In eight cases they were found in the kidneys only, usually in the convoluted tubules, and almost invariably associated with a mild inflammatory reaction. It is noteworthy that one of these had cirrhosis (de Lange, 1922) and another hepatitis (Müller, 1922), although those described by Ribbert (1904), Lowenstein (1907), Jackson (1922), and Silbergleit (1938) showed unrelated lesions.

Mouchet (1911) found typical cells in the liver of a case of cirrhosis aged 8 days. The only other incidental finding in the liver was by McCordock and Smith (1934) in a child dying of cerebral haemorrhage.

\section{Summary}

Four cases of generalized infection by the salivary gland virus, and six cases with inclusion bodies in one or two organs only are described.

A review of the literature shows early death and frequent prematurity to be common. The most common clinical picture in infants dying within two days of birth is composed of jaundice, purpura, hepatosplenomegaly and erythroblastaemia with diminution of blood platelets. Other common clinical features 
are cerebral calcification, cough often associated with pneumonitis, whooping cough, and cystic fibrosis of the pancreas, and gastro-intestinal symptoms, especially diarrhoea.

At necropsy the organs most commonly affected are the lungs, kidneys, liver, pancreas, and salivary glands. Those less commonly affected are the thyroid, adrenals, pituitary, parathyroids, brain, intestine, epididymis, spleen, eye, amd skin. Signs of dysfunction of the affected organs are usually lacking. This is especially true of the endocrine glands, although an exception is found in one case of the present series where thyroiditis with hypothyroidism was present.

While generalized infection must be considered to be a rare condition, affection of one or two organs, particularly the salivary glands, is not infrequent.

I wish to thank Dr. Beryl Paige, of the Babies Hospital, New York, for permission to publish Cases 2 to 7 and Cases 9 and 10, and Drs. Mary Wilmers and C. T. Potter of the Queen Elizabeth Hospital for Children, London, for Cases 1 and 8 . I am greatly indebted to Drs. Dorothy H. Andersen and Mary Wilmers for their help, encouragement, and criticism, and to Miss F. M. Humphries and Mr. J. O'Neill for their technical assistance.

\section{REFERENCES}

Andrews, H. S., and Miller, A. J. (1935). Amer.J. Dis. Child., 50, 673.

Blackman, S. S. (1936). Bull. Johns Hopk. Hosp., 58, 383.

Cappell, D. F., and McFarlane, M. N. (1947). J. Path. Bact., 59, 385.

Cole, R., and Kuttner, A. G. (1926). J. exp. Med., 44, 855 .

Cowdry, E. V. (1934). Arch. Path. Chicago, 18, 527.

- - Lucas, A. M., and Fox, H. (1935). Amer. J. Path., 11, 237.

-

$\longrightarrow$ - (1935b). Ibid., 11, 659.
Farber, S., and Wolbach, S. B. (1932). Ibid., 8, 123.

Feyrter, F. (1927). Frankfurt. Z. Path., 35, 213.

Goodpasture, E. W., and Talbot, F. B. (1921). Amer. J. Dis. Child., 21, 415.

Jackson, L. (1920). J. infect. Dis., 26, 347.

- (1922). Ibid., 30, 636.

Jesionek and Kiolemenoglou (1904). Münch. med. Wschr., 51, 1905.

Kalfayan, B. (1947). Arch. Path. Chicago, 44, 467.

Kinney, T. D. (1942). Amer. J. Path., 18, 799.

Kuttner, A., and Wang, S. H. (1934). J. exp. Med., 60, 773.

Lange, C. de (1922). Virchows Arch., 237, 276.

Lee, J. (1933). Proc. Soc. exp. Biol., N.Y., 31, 383.

Lowenstein, C. (1907). Zbl. allg. Path. path. Anat., $18,513$.

McCordock, H. A., and Smith, M. G. (1934). Amer. J. Dis. Child., 47, 771.

Markham, F. S. (1938). Amer. J. Path., 14, 311.

Mouchet, R. (1911). Arch. Méd. exp., 23, 115.

Müller, J. (1922). Virchows Arch., 238, 481.

Olitsky, P. K., and Harford, C. G. (1937). Amer. J. Path., 13, 729.

Pearson, E. F. (1930). Amer. J. Path., 6, 261.

Pettavel, C. A. (1911). Virchows Arch., 206, 1.

Pinkerton, H. (1950). Amer. J. clin. Path., 20, 201.

Pisano, G. (1910). Gazz. Osp. Clin., 31, 249.

Rector, E. J., and Rector, L. E. (1934). Amer. J. Path., $10,629$.

Ribbert, H. (1904). Zbl. allg. Path. path. Anat., 15, 945.

Rich, A. R. (1932). Bull. Johns Hopk. Hosp., 51, 346.

Rosenbusch, C. T., and Lucas, A. M. (1939). Amer. J. Path., 15, 303.

Silbergleit, W. H. (1938). Pathologica, 30, 181.

Smith, A. J., and Weidman, F. D. (1910). Univ. Pa. med. Bull., 23, 285.

Thompson, J. (1934). Amer. J. Path., 10, 676.

Thompson, M. J. (1932). J. infect. Dis., 50, 162.

Tyzzer, E. E. (1906). J. med. Res., 14, 361.

Vidari, E. (1940). Zibl. allg. Path. path. Anat., 76, 161.

Wagner, H. (1930). Beitr. path. Anat., 85, 145.

Walz, K. (1926). Verh. dtsch. path. Ges., 21, 236.

Wanstrom, R. C. (1933). Amer. J. Path., 9, 623.

Worth, W. A., and Howard, H. L. (1950). Ibid., 26, 17.

Wyatt; J. P., Saxton, J., Lee, R. S., and Pinkerton, H. (1950). J. Pediat., 36, 271. 